\title{
BMJ Open Vision-specific risk factors impacting self-rated health among older men in urban China: a population-based cross- sectional study
}

\author{
Wei Yang, ${ }^{1}$ Jinsong Han, ${ }^{2}$ Bowen Wang, ${ }^{2}$ Tianjiao Zhang, ${ }^{2}$ Wei Sun (1) ${ }^{2}$
}

To cite: Yang W, Han J, Wang B, et al. Vision-specific risk factors impacting self-rated health among older men in urban China: a population-based cross-sectional study. BMJ Open 2021;11:e054435. doi:10.1136/ bmjopen-2021-054435

- Prepublication history and additional supplemental material for this paper are available online. To view these files, please visit the journal online (http://dx.doi.org/10.1136/ bmjopen-2021-054435).

Received 11 June 2021 Accepted 02 December 2021

D Check for updates

(c) Author(s) (or their employer(s)) 2021. Re-use permitted under CC BY-NC. No commercial re-use. See rights and permissions. Published by BMJ.

${ }^{1}$ Department of Thoracic Surgery Medicine, China Medical University Shengjing Hospital Nanhu Branch, Shenyang, Liaoning, China

${ }^{2}$ Research Center for Universal Health, School of Public Health, China Medical University, Shenyang, China

Correspondence to Wei Sun; wsun@cmu.edu.cn

\section{ABSTRACT}

Background Self-rated health (SRH) has been well documented as an important assessment of health status among the older adults. Interestingly, visual ability has been reported to have a considerable impact on the quality of life of the older adults. This study clarified vision-specific risk factors impacting SRH among older men without cognitive impairment in order to optimise healthcare for the older adults.

Methods A population-based cross-sectional study was conducted in urban areas of Liaoning Province. A stratified sampling method was used and all men aged $\geq 65$ years and living in sampled communities without dementia were interviewed between March and November 2012. $\mathrm{SRH}$, visual ability and factors including demographic characteristics, physical conditions, lifestyle factors, social psychological factors and social activities, were measured. 1884 effective responses were received (effective response rate, $84.8 \%$ ) and 1724 individuals were enrolled after further cognitive screening.

Results The mean age was $72.9 \pm 5.9$ (mean \pm SD). Of individuals with good and poor visual ability, $38.3 \%$ and $33.0 \%$ reported good SRH, respectively. The characteristics between different visual ability groups were significantly different. Interactions between visual ability and four items had significant effects on SRH. In good visual ability group, chronic disease had the strongest association with good SRH followed by participating in entertainment, taking a walk, filial piety and alcohol consumption. In poor visual ability group, taking a walk had the strongest association with good SRH followed by participating in entertainment, hearing ability, smoking, quality of sleep, going out alone to distant places and alcohol consumption.

Conclusions A good SRH status, even among the individuals with good visual ability, had a low prevalence among older men in urban areas. The risk factors impacting SRH was vision-specific. Physical conditions were crucial for SRH among those with good visual ability. In contrast, lifestyle factors were prominent for those with poor visual ability.

\section{INTRODUCTION}

In the twenty-first century, population ageing has become a global issue. ${ }^{12}$ China is a nation with the largest ageing population in the world ( $20 \%$ of the global aged population).
Strengths and limitations of this study

- Visual-specific risk factors to self-rated health (SRH) were clarified due to the considerable effect of vision ability on the health status of the older adults.

- Subjective visual ability that was able to reflect the practical ability and more global visual problems in the daily life of the older adults was explored as the indicator of visual ability instead of objective measurements.

- The interactions of vision ability with risk factors to SRH in the total population were clarified.

- Exclusion of information bias was ensured as sufficient as possible because both dementia diagnosis and further mini-mental state examination were performed to screen the cognitive function of the older adults.

From 2000 to 2020, the percentage of people $\geq 65$ years of age increased from $7.0 \%$ to $13.5 \%$, as reported by the National Bureau of Statistics of China. ${ }^{3}$ Unfortunately, economic development in China is lagging far behind the ageing population. Thus, it is crucial to maintain and/or improve the quality of life of the aged population in China.

Self-rated health (SRH) is a subjective assessment of health status. The perception of SRH integrates physical, psychological and social function. Thus, even if SRH is only a single question, SRH has been validated to be a reliable predictor of disability and mortality of the older adults and is able to identify the population with a high risk of health service use and cost. ${ }^{4-7}$ Studies involving SRH of the older adults have been conducted internationally and in China. ${ }^{45-12}$

Visual ability has been well documented to have a considerable effect on the health status of the older adults. In addition to $\mathrm{SRH},{ }^{13}$ visual impairment, as assessed through objective tests, has been associated with increased risk of falls among the older adults. ${ }^{14}$ 
Self-reported visual problems have been reported to worsen physical function, and cognitive and psychological health, such as confusion, depression, life satisfaction and social isolation. ${ }^{15-18}$ The effect of visual ability on health-related quality of life is even stronger than the effect of type 2 diabetes mellitus, coronary syndrome and hearing impairment. ${ }^{19}$ In considering the prominent effect of visual ability on health status of the older adults, we do believe it is necessary to study SRH and its risk factors separately in people with different visual abilities with the purpose of optimising healthcare for the older adults. Moreover, according to our knowledge, cognitive function screening among the ageing population has not been thoroughly evaluated in previous studies on SRH. Older adults with cognitive impairment, but not as severe as dementia, were included in previous study populations, ${ }^{5-1012}$ which leads to the information bias and inevitably weakens the generalisation of the conclusions.

We designed the present study to assess SRH and clarify vision-specific risk factors among the older adults without cognitive impairment. Since SRH had sex-specific difference $^{45811}$ and the prevalence of moderate/severe vision impairment also differed between Chinese older men $(8.1 \%)$ and Chinese older women $(9.4 \%),{ }^{20}$ we would like to report SRH separately in men and women. Because life expectancy in men (73.6 years) is not as long as women (79.4 years) as reported by National Bureau of Statistics of China, ${ }^{3}$ we initially focused on older men in urban areas of China. The following risk factors have been shown to be related to SRH: age; living arrangement; socioeconomic status; chronic disease; sensory impairment; mobility; diet; physical exercise; social network and depressive symptoms. ${ }^{45-12}$ Therefore, these factors were involved in the assessment for the current study. In addition, because Confucianism is the traditional view in China and has an important influence on Chinese spirit, the filial duty of children was also taken into account. After cognitive function screening, the SRH, visual ability and related factors, such as demographic characteristics, physical condition, lifestyle factors, social psychological status and social activities, were measured and assessed. We believe that our conclusions will contribute to health promotion in the older adults.

\section{METHODS}

\section{Study area and study population}

The present cross-sectional study was conducted in Shenyang city and Anshan city in Liaoning province in China, where the income level is similar to the national average and there are 14 cities (56 administrative districts). The stratified cluster random sampling method was used. Four districts were selected randomly from two cities. One community from each sampled district was randomly selected. The detail study design has been previously described. ${ }^{21}$ All men $(n=2221)$ who were $\geq 65$ years of age, were not diagnosed with dementia, lived in the local area for $>5$ years and could be persuade to take part in this study, comprised our study population. This study population accounted for $26.5 \%$ of the Chinese older men who had lived in the sampled communities for $>0.5$ year and left for $<0.5$ year. All individuals were interviewed in their home by trained investigators who were recruited from graduate students majoring in medical epidemiology and had undergone 2 weeks of specialised training. Completion of $\geq 80 \%$ of the interview was defined as an effective response. A total of 1884 effective responses were received (effective response rate, $84.8 \%$ ). Finally, 1724 individuals became our subjects after further cognitive function screening with the mini-mental state examination (MMSE). The sampling frame is shown in online supplemental figure 1. Data were collected between March and November 2012.

\section{Cognitive function screening}

Cognitive function screening was assessed using the MMSE. This instrument has been widely and successfully used among the ageing population in China. ${ }^{22}{ }^{23}$ The MMSE includes 19 items and reflects the abilities of orientation, registration, calculation, recall, naming, repetition, comprehension, writing and construction. It has been applied extensively to grade cognitive impairment. The total score ranges from 0 to 30 . Even though most western countries employed 23/24 as the cut-off point in cognitive impairment screening, ${ }^{24}$ the education levels among the aged population are different between China and western countries. The cut-off point drawn from Chinese population was reported to be $16 / 17$ for illiterate, 19/20 for 1-6 years of education and 23/24 for seven or more years of education. ${ }^{25}$ However, the length of education for elementary school has changed from 5 years to 6 years just since 1986 in China, which is quite different with the school system experienced by those older adults. Thus, we prefer to adopt the cut-off points according to the school system rather than the length of education for the aged population. In our study, the MMSE score cut-off values for cognitive impairment were as follows: $\leq 17$, illiterate; $\leq 20$, elementary; $\leq 22$, middle/ high school and $\leq 23$ for junior college and over. ${ }^{22}$

\section{Assessment of SRH}

The examination of SRH referred to our previous study, which was conducted among non-disabled older adults living alone in Japan. ${ }^{11}$ SRH was measured by asking the following question: "what do you think of your health in general?' The answers included 'excellent', 'good', 'fair' and 'poor'. Even if the responses included different levels of health status, the studies conducted in Brazil, Chile, Japan, Spain and Australia ${ }^{5} 91213$ dichotomised the responses. Since SRH is a perceived health indicator indicating an integrated assessment, the identification of the outcome was prior for the evaluation. We do think that the dichotomised outcomes have higher identification than the original responses. Moreover, the comparison of the findings could increase the feasibility of assessment on SRH levels among different populations. Due to these 
facts, the outcomes of this study were also dichotomised as 'good' or 'poor' by combining answer one with answer two and answer three with answer four.

\section{Measurements of visual ability and related factors, including demographic characteristics, physical condition, lifestyle factors, social psychological status and social activities}

Visual ability was assessed based on the subjective, but practical ability in the daily life of the older adults, not the objective visual acuity, visual field or visual sensitivity. With respect to the measurement of vision, Horowitz ${ }^{26}$ concluded that compared with objective measurement, subjective measurement of vision reflects more global visual problems, such as trouble seeing and difficulty reading and has an important influence in the daily life of an individual. Performance-based measurement of visual function can offer an objective assessment, but does not assess the impairment due to perception problems. Thereby, it has the possibility to offer a more exclusive estimate of visual problems. On the contrary, subjective measurement tends to offer a more inclusive estimate. Bookwala $e t a l^{16}$ also concluded that self-reported vision is able to predict depressive symptoms in older adults through both direct and indirect pathways, whereas this effect was not observed for objective vision ability. Thus, a subjective measure was selected to indicate vision ability in this study, although a performance-based measure would have been more objective. We prepared the newspapers and asked the participants to read the newspaper whether or not wearing glasses or corrective lenses. The condition of wearing glasses or corrective lenses was just kept the same as the usual status in the participants' daily life. For the illiterate older adults, the clearness of watching was asked and the numbers included in the newspaper were picked out for read. The visual ability was defined as 'good' if the participants could see the newspaper or numbers clearly and correctly; otherwise, the visual ability was defined as 'poor'. ${ }^{27}$

The demographic characteristics included the following five items: (1) age; (2) marital status; (3) living arrangement; (4) pension and (5) health insurance. For marital status, the responses of 'single', 'divorced' and 'separated' were combined with the response of 'widow' as the 'other' group based on a low ratio $(<1.0 \%)$. Living arrangement was defined as 'living alone' and 'living with others' (such as a spouse and children). Pension and health insurance were dichotomised as 'have' and 'have not' groups.

The physical condition was assessed by the following five items: (1) chronic disease; (2) hearing ability; (3) quality of sleep; (4) going out alone to distant places and (5) worrying about falling. Chronic disease, hearing ability, going out alone to distant places and worrying about falling were measured by referring to our previous study conducted in Japan. ${ }^{11}$ Chronic disease was defined as 'present' if hypertension, cardiovascular disease, diabetes, stroke, liver cirrhosis, emphysema, rheumatoid arthritis and chronic renal insufficiency had been diagnosed. Hearing ability was assessed by asking whether they need the voice/volume to be raised while conversation/watching television. Quality of sleep was assessed by asking whether the participants had difficulty in falling asleep or if waking/dreaming occurred frequently during sleeping.

The lifestyle factors were comprised of the following four items: (1) taking a walk; (2) smoking; (3) alcohol consumption and (4) regular diets. Taking a walk was assessed by a frequency of ' $\geq 3-4$ times/week' or ' $\leq 1-2$ times/week'. Smoking was measured and categorised as 'yes/had ever' or 'never.' Alcohol consumption was defined as 'yes' or 'no'. ${ }^{11}$ Regular diets were assessed by asking whether the participants have breakfast, lunch and dinner on time. ${ }^{11}$

The social psychological status was evaluated based on the following two items: (1) depressive symptoms and (2) filial piety. Depressive symptoms were assessed using the Geriatric Depression Scale (GDS-15). ${ }^{28}$ Filial piety was determined by the following question: 'What do you think about your children's filial piety to you?' The responses were divided into two groups (good (very good/good) and poor (so so/bad)). In this study, participants who had no any child or whose children had passed away accounted for $2.15 \%$. These individuals were also included in 'poor' group due to the ratio $<5 \%$.

The social activities included the following two items: (1) participating in entertainment and (2) watching television frequently. Participating in entertainment measured the status of an individual frequently playing mahjong, chess or cards with others or looking around. ${ }^{21}$ To establish if the participant watched television, the following question was asked: 'Do you watch television frequently?' Participating in entertainment and watching television frequently were defined as 'yes' or 'no'.

\section{Patient and public involvement}

No patient involved.

\section{Statistical analysis}

Data were analysed separately in the good and poor visual ability groups. Health insurance in both groups $(99 \%$ and $97.4 \%$, respectively) and pension in the good visual ability group (95.9\%) were excluded because $>95 \%$ of the responders had the same responses.

The difference in subject characteristics between the visual ability groups and the distribution of SRH among the categorical variables were examined using a $\chi^{2}$ test. The association of SRH with risk factors was identified by multivariate logistic regression. Vision-specific associations with SRH were examined by stepwise multivariate logistic regression. The model included all risk factors identified in the total study population and the interaction terms of visual ability with each risk factor. In view of the prominent difference of characteristics between individuals with good and impaired visual ability and the vision-specific results, we further clarified risk factors to 
SRH separately for older men with good visual ability and older men with impaired visual ability.

The agreement among categorical variables was determined based on Kappa test. The variables were considered in agreement if Kappa values was $>0.50$. In this study, marital status and living arrangement were in agreement (kappa $=0.786$ in the good visual ability group and kappa $=0.541$ in the poor visual ability group), and living arrangement and filial piety were in agreement in the poor visual ability group (kappa $=0.565$ ). Thus, these items were adjusted when performing multivariate analysis.

The data are shown as a number $(\mathrm{N})$, prevalence $(\%)$, OR and 95\% CI. Age was used as a continuous variable and shown as mean \pm SD. The missing data would be handled only if the missing rate was $>5 \% .{ }^{21}$ In this study, no missing data needed to be handled. SAS for Windows, V.8.2, was used to perform data analysis.

\section{RESULTS}

The study population comprised of 1724 communitydwelling Chinese older men aged 65-92 years and without cognitive impairment. The mean age was $72.9 \pm 5.9$ $($ mean $\pm \mathrm{SD})$. The age difference was significant between the good $(72.2 \pm 5.7)$ and poor $(73.9 \pm 6.0)$ visual ability groups $(\mathrm{p}<0.05)$. The comparison of subject characteristics between the good and poor visual ability groups is shown in table 1 . The older men in the good visual ability group more frequently reported good SRH than those in the poor visual ability group $(p<0.05)$. Between the two groups, the differences in most items (demographic characteristics, physical condition, social psychological status and social activities) were significant $(\mathrm{p}<0.05)$; however, no difference was found in lifestyle factors $(\mathrm{p}>0.05)$.

Univariate analysis of factors related to good SRH among the older men with different visual ability is shown in table 2. For individuals with good visual ability, chronic disease, quality of sleep, going out alone to distant places, worrying about falling, taking a walk, alcohol consumption, regular diet, depressive symptoms and participating in entertainment were significantly correlated with good SRH. In contrast, marital status, all physical condition items, taking a walk, smoking, regular diets, all social psychological factor items and all social activity items were related to good SRH for older men with poor visual ability. According to the OR, older men without chronic disease were five times more likely to report good SRH than those with chronic disease $(\mathrm{OR}=5.39)$ in the good visual ability group; whereas individuals who did take a walk were 10 times more likely to report good SRH than those who did not $(\mathrm{OR}=10.17)$ in the poor visual ability group. Their OR values were the highest in each group.

Results of multivariate logistic regression analyses in the total study population are shown in table 3. After fixing age in the model as a continuous variable, good SRH was associated with, in OR sequence, absence of chronic disease, participating in entertainment (yes), more frequently taking a walk, good quality of sleep, filial
Table 1 The comparison of subject characteristics between the good and poor visual ability groups

\begin{tabular}{|c|c|c|c|}
\hline Variables & $\begin{array}{l}\text { Good visual } \\
\text { ability (1033) } \\
\text { N (\%) }\end{array}$ & $\begin{array}{l}\text { Poor visual } \\
\text { ability (691) } \\
\text { N (\%) }\end{array}$ & P value \\
\hline Good SRH & $396(38.3)$ & $228(33.0)$ & 0.025 \\
\hline \multicolumn{4}{|l|}{$\begin{array}{l}\text { Demographic } \\
\text { characteristics }\end{array}$} \\
\hline \multicolumn{4}{|l|}{ Age } \\
\hline $75+$ & $292(28.3)$ & $288(41.7)$ & \\
\hline $65-74$ & $741(71.7)$ & 403 (58.3) & 0.000 \\
\hline \multicolumn{4}{|l|}{ Marital status } \\
\hline Other & $160(15.5)$ & $141(20.4)$ & \\
\hline Married/cohabitation & $873(84.5)$ & $549(79.6)$ & 0.010 \\
\hline \multicolumn{4}{|l|}{ Living arrangement } \\
\hline Living alone & $113(10.9)$ & $71(10.3)$ & \\
\hline Living with others & $919(89.1)$ & $619(89.7)$ & 0.691 \\
\hline \multicolumn{4}{|l|}{ Pension } \\
\hline Have not & $42(4.1)$ & $74(10.7)$ & \\
\hline Have & 988 (95.9) & $616(89.3)$ & 0.000 \\
\hline \multicolumn{4}{|l|}{ Physical condition } \\
\hline \multicolumn{4}{|l|}{ Chronic disease } \\
\hline Present & $695(67.3)$ & $567(82.1)$ & \\
\hline Not present & $338(32.7)$ & $124(17.9)$ & 0.000 \\
\hline \multicolumn{4}{|l|}{ Hearing ability } \\
\hline Impaired & 306 (29.6) & $457(66.2)$ & \\
\hline Good & $727(70.4)$ & 233 (33.8) & 0.000 \\
\hline \multicolumn{4}{|l|}{ Quality of sleep } \\
\hline Impaired & $388(37.6)$ & $377(54.6)$ & \\
\hline Good & $645(62.4)$ & $314(45.4)$ & 0.000 \\
\hline \multicolumn{4}{|l|}{$\begin{array}{l}\text { Going out alone to } \\
\text { distant places }\end{array}$} \\
\hline Cannot & $518(50.1)$ & $492(71.2)$ & \\
\hline Can & $515(49.9)$ & 199 (28.8) & 0.000 \\
\hline
\end{tabular}

Worrying about

falling

\begin{tabular}{llll} 
Yes & $427(41.4)$ & $253(36.7)$ & \\
No & $605(58.6)$ & $437(63.3)$ & 0.056 \\
$\begin{array}{l}\text { Lifestyle factors } \\
\text { Taking a walk }\end{array}$ & & & \\
$\leq 1-2$ times/week & $410(39.7)$ & $300(43.4)$ & \\
$\geq 3-4$ times/week & $623(60.3)$ & $391(56.6)$ & 0.134 \\
\hline $\begin{array}{l}\text { Smoking } \\
\text { Yes/had ever }\end{array}$ & $597(58.0)$ & $427(61.8)$ & \\
\hline Never & $432(42.0)$ & $264(38.2)$ & 0.121 \\
$\begin{array}{l}\text { Alcohol } \\
\text { consumption }\end{array}$ & & & \\
Yes & $464(45.0)$ & $286(41.6)$ & \\
\hline No & $566(55.0)$ & $401(58.4)$ & 0.165 \\
\hline & & & Continued \\
\hline
\end{tabular}




\begin{tabular}{|c|c|c|c|}
\hline Variables & $\begin{array}{l}\text { Good visual } \\
\text { ability (1033) } \\
\text { N (\%) }\end{array}$ & $\begin{array}{l}\text { Poor visual } \\
\text { ability (691) } \\
\text { N (\%) }\end{array}$ & $P$ value \\
\hline \multicolumn{4}{|l|}{ Regular diet } \\
\hline No & 127 (12.3) & $74(10.7)$ & \\
\hline Yes & $906(87.7)$ & 617 (89.3) & 0.321 \\
\hline \multicolumn{4}{|c|}{$\begin{array}{l}\text { Social } \\
\text { psychological } \\
\text { status }\end{array}$} \\
\hline \multicolumn{4}{|c|}{$\begin{array}{l}\text { Depressive } \\
\text { symptoms }\end{array}$} \\
\hline Present & 133 (12.9) & 249 (36.0) & \\
\hline Not present & $899(87.1)$ & $442(64.0)$ & 0.000 \\
\hline \multicolumn{4}{|l|}{ Filial piety } \\
\hline Poor & 99 (9.6) & 77 (11.3) & \\
\hline Good & $928(90.4)$ & $602(88.7)$ & 0.290 \\
\hline \multicolumn{4}{|c|}{ Social activities } \\
\hline \multicolumn{4}{|c|}{$\begin{array}{l}\text { Participating in } \\
\text { entertainment }\end{array}$} \\
\hline No & 278 (27.0) & $336(48.8)$ & \\
\hline Yes & 753 (73.0) & $353(51.2)$ & 0.000 \\
\hline \multicolumn{4}{|c|}{$\begin{array}{l}\text { Watching television } \\
\text { frequently }\end{array}$} \\
\hline No & $116(11.2)$ & $102(14.8)$ & \\
\hline Yes & $916(88.8)$ & $589(85.2)$ & 0.032 \\
\hline
\end{tabular}

$\mathrm{SRH}$, self-rated health.

piety (good), never smoking, 'can go out alone to distant places', good visual ability and no alcohol consumption. Interesting, the association between SRH and visual ability was reverse that good visual ability was related to impaired SRH.

Results of stepwise multivariate logistic regression analysis are shown in table 4. Vision-specific associations with good SRH were examined by entering all risk factors and interaction terms of visual ability with each risk factor identified among the total population. Of all risk factors, age, participating in entertainment, smoking and taking a walk were found to have stronger associations with SRH in individuals with good visual ability than those with impaired visual ability.

The multivariate logistic regression analysis of the factors associated with good SRH among the older men with different visual ability is shown in table 5. Age was adjusted in the model and the associations were shown in OR sequence. Good SRH was associated with chronic disease (not present), participating in entertainment (yes), taking a walk ( $\geq 3-4$ times/week), filial piety (good) and alcohol consumption (yes) in the good visual ability group. Good SRH was associated with taking a walk ( $\geq 3-4$ times/week), participating in entertainment (yes), hearing ability (good), smoking (never), quality of sleep (good), going out alone to distant places (can) and alcohol consumption (yes) in the poor visual ability group.

\section{DISCUSSION}

Our study population comprised 1724 communitydwelling Chinese older men, more than a quarter out of the total male inhabitants in sampled areas. Meanwhile, the cities sampled in this study could represent the urban area according to the Liaoning Provincial Yearbook 2012. Thus, the findings could be generalised to the whole province. In this study, a comparison of characteristics between individuals in the good and poor visual ability groups revealed that the difference was considerable, which was in agreement with previous conclusions. ${ }^{14-17}$ Further analysis indicated that the prevalence of good SRH differed between individuals with good and poor visual ability. The vision-specific attention was caught when the reverse association was found while clarifying risk factors among the total study population. Thereby, the interactions between visual ability and other risk factors identified were performed. It was revealed that men with poor visual ability were older and more likely to have chronic disease, impaired hearing ability, impaired quality of sleep, deteriorated mobility, depressive symptoms and less social activities, in comparison to those with good visual ability. Those facts confirmed our hypothesis that visual-appropriate healthcare might be more valuable for the perceived assessment of health status among the older men.

With respect to the assessment of good SRH, older men with good visual ability were likely to report good SRH $(38.3 \%)$ than those with poor visual ability $(33.0 \%)$; however, the prevalence in the good visual ability group was still significantly lower than that reported by community-dwelling men $(58.0 \%)$ with an average age of 70.7 years in Brazil. ${ }^{5}$ Compared with the prevalence $(63.3 \%)$ drawn from older adults including both men and women aged 60 years and over in rural areas of south China, ${ }^{10}$ good SRH of our study population was also at a lower level. These findings revealed that the good SRH status of older men in urban areas of China might be at a low level. Due to the potential of SRH predicting functional disability and mortality of the older adults, how to maintain and/or improve SRH of the older men in urban China seems to be urgent for the quality of life of the aged population.

With respect to the risk factors, chronic disease had the strongest association with SRH among individuals with good visual ability. The older adults are a high-risk population for chronic disease due to functional ageing. ${ }^{2}$ The presence of chronic disease leads to a poor physical condition ${ }^{29}$ and influences the SRH; however, the effect was not found among older men with poor visual ability. For those with poor visual ability, taking a walk was the strongest associated factor affecting SRH. The OR value was 6.10 , whereas the OR value was only 1.79 for older men with good visual ability. 
Table 2 Univariate analysis of factors related to good SRH among the older men with different visual ability

Good visual ability

( $n=1033)$

Variables

Demographic characteristics

Age

$75+$

65-74

Marital status

Other

Married/cohabitation

Living arrangement

Living alone

Living with others

Pension

Have not

Have

Physical condition

Chronic disease

Present

$59(36.9)$

337 (38.6)

$45(39.8)$

$351(38.2)$

$-$

85 (29.1)

$311(42.0)$

1.76 (1.32 to 2.36$) \quad 168(41.7)$

$21(14.9)$

1.08 (0.76 to 1.53$) \quad 207(37.7)$

3.46 (2.11 to 5.67$)$

Not present

Hearing ability

Impaired

Good

Good

Going out alone to distant places

Cannot

Can

Worrying about falling

Yes

No

Lifestyle factors

Taking a walk

$\leq 1-2$ times/week

23-4 times/week
Poor visual ability

( $\mathrm{n}=691$ )

Good SRH N (\%) OR $(95 \% \mathrm{Cl})$

\section{Smoking}

Yes/had ever

$11(15.5)$

0.93 (0.63 to 1.39$) \quad 217(35.1)$

2.94 (1.52 to 5.72$)$

Never

Alcohol consumption

Yes

No

Regular diet

No

Yes
$177(25.5)$

$219(64.8)$

$-$

$118(38.6)$

278 (38.2)

$122(31.4)$

$274(42.5)$

$118(28.8)$

$278(44.6)$

$221(37.0)$

$174(40.3)$

$210(45.3)$

$185(32.7)$

$35(27.6)$

$361(39.8)$

$140(32.8)$

$143(27.6)$

$(21.1)$

$21(28.4)$

207 (33.6)

1.28 (0.75 to 2.18$)$

4.32 (2.88 to 6.49$)$

$5.39(4.07$ to 7.13$) \quad 76(61.3)$

5.23 (3.70 to 7.38$)$

$34(57.5)$

76 (20.2)

1.61 (1.24 to 2.10$) \quad 152(48.4)$

$3.72(2.66$ to 5.20$)$

$256(42.3)$

1.50 (1.16 to 1.95$) \quad 188(43.0)$

4.02 (2.73 to 5.92$)$

6.17 (4.31 to 8.83$)$

2.53 (1.96 to 3.28$) \quad 124$ (62.3)

$40(15.8)$

8 (9.3)

1.99 (1.53 to 2.60) 200 (51.2)

10.17 (6.57 to 15.74$)$

88 (20.6)

1.15 (0.89 to 1.48$) \quad 140(53.0)$

4.35 (3.11 to 6.09$)$

$102(35.7)$

0.59 (0.46 to 0.76$) \quad 124(30.9)$

0.81 (0.59 to 1.11$)$

$14(18.9)$

$214(34.7)$

2.28 (1.24 to 4.17$)$

Social psychological status 
Table 2 Continued

\begin{tabular}{|c|c|c|c|c|}
\hline \multirow[b]{2}{*}{ Variables } & \multicolumn{2}{|c|}{$\begin{array}{l}\text { Good visual ability } \\
(n=1033)\end{array}$} & \multicolumn{2}{|l|}{$\begin{array}{l}\text { Poor visual ability } \\
(n=691)\end{array}$} \\
\hline & Good SRH N (\%) & OR $(95 \% \mathrm{Cl})$ & Good SRH N (\%) & OR (95\% Cl) \\
\hline \multicolumn{5}{|c|}{ Depressive symptoms } \\
\hline Present & $25(18.8)$ & & $98(39.4)$ & \\
\hline Not present & $371(41.3)$ & 3.04 (1.93 to 4.78$)$ & $130(29.4)$ & 0.64 (0.46 to 0.89$)$ \\
\hline \multicolumn{5}{|l|}{ Filial piety } \\
\hline Poor & $30(30.3)$ & & $12(15.6)$ & \\
\hline Good & 364 (39.2) & 1.48 (0.95 to 2.32$)$ & $214(35.5)$ & 2.99 (1.58 to 5.66$)$ \\
\hline \multicolumn{5}{|c|}{ Social activities } \\
\hline \multicolumn{5}{|c|}{ Participating in entertainment } \\
\hline No & $61(21.9)$ & & 39 (11.6) & \\
\hline Yes & $334(44.4)$ & 2.84 (2.06 to 3.90$)$ & 189 (53.5) & 8.78 (5.92 to 13.01$)$ \\
\hline \multicolumn{5}{|c|}{ Watching television frequently } \\
\hline No & $36(31.0)$ & & $19(18.6)$ & \\
\hline Yes & $359(39.2)$ & 1.43 (0.95 to 2.17$)$ & $209(35.5)$ & 2.40 (1.42 to 4.07$)$ \\
\hline
\end{tabular}

$\mathrm{SRH}$, self-rated health.

Poor visual ability increases mobility difficulties. It has been reported that compared with those with good visual ability, people with impaired visual ability have lower walking speed and more falls. ${ }^{140-32}$ Decreased walking ability would inevitably confine their daily activities, regardless of the physical conditions. For the older adults with poor visual ability, taking

Table 3 The multivariate logistic regression analysis of the factors associated with good SRH among the total population

\begin{tabular}{lll}
\hline & \multicolumn{2}{l}{ OR } \\
\cline { 2 - 3 } Variables & Value & $\mathbf{9 5 \%} \mathbf{C l}$ \\
\hline $\begin{array}{l}\text { Age (years) } \\
\text { Chronic disease (not present } \\
\text { vs present) }\end{array}$ & 0.96 & 0.94 to 0.98 \\
\hline $\begin{array}{l}\text { Participating in entertainment } \\
\text { (yes vs no) }\end{array}$ & 2.80 & 2.49 to 4.30 \\
$\begin{array}{l}\text { Taking a walk ( } \geq 3-4 \text { times/ } \\
\text { week vs } \leq 1-2 \text { times/week) }\end{array}$ & 2.57 & 2.12 to 3.69 \\
$\begin{array}{l}\text { Quality of sleep (good vs } \\
\text { impaired) }\end{array}$ & 1.56 & 1.99 to 3.33 \\
\hline $\begin{array}{l}\text { Filial piety (good vs poor) } \\
\begin{array}{l}\text { Smoking (never vs yes/had } \\
\text { ever) }\end{array}\end{array}$ & 1.54 & 1.22 to 2.00 \\
$\begin{array}{l}\text { Going out alone to distant } \\
\text { places (can vs cannot) }\end{array}$ & 1.40 & 1.01 to 2.34 \\
\hline $\begin{array}{l}\text { Visual ability (good vs poor) } \\
\text { Alcohol consumption (no vs } \\
\text { yes) }\end{array}$ & 0.67 & 1.11 to 1.86 \\
\hline
\end{tabular}

${ }^{\mathrm{a}} \mathrm{Age}$ was treated as continuous variable and fixed in the model. $\mathrm{SRH}$, self-rated health.
Table 4 Stepwise multivariate logistic regression analysis of vision-specific associations with good $\mathrm{SRH}$

\begin{tabular}{|c|c|c|}
\hline \multirow[b]{2}{*}{ Variables } & \multicolumn{2}{|l|}{ OR } \\
\hline & Value & $95 \% \mathrm{Cl}$ \\
\hline \multicolumn{3}{|l|}{ Total population $(n=1707)$} \\
\hline Age (years) ${ }^{a}$ & 0.94 & 0.92 to 0.96 \\
\hline $\begin{array}{l}\text { Taking a walk ( } \geq 3-4 \text { times/week } \\
\text { vs } \leq 1-2 \text { times/week) }\end{array}$ & 6.56 & 3.959 to 10.90 \\
\hline $\begin{array}{l}\text { Participating in entertainment (yes } \\
\text { vs no) }\end{array}$ & 4.03 & 2.56 to 6.37 \\
\hline $\begin{array}{l}\text { Chronic disease (not present vs } \\
\text { present) }\end{array}$ & 3.44 & 2.60 to 4.54 \\
\hline Smoking (never vs yes/had ever) & 2.47 & 1.61 to 3.79 \\
\hline Filial piety (good vs poor) & 1.61 & 1.05 to 2.46 \\
\hline Quality of sleep (good vs impaired) & 1.50 & 1.17 to 1.93 \\
\hline $\begin{array}{l}\text { Going out alone to distant places } \\
\text { (can vs cannot) }\end{array}$ & 1.41 & 1.07 to 1.85 \\
\hline Visual ability (good/impaired)ªge & 1.03 & 1.02 to 1.05 \\
\hline $\begin{array}{l}\text { Visual ability (good/ } \\
\text { impaired)* participating in } \\
\text { entertainment (yes vs no) }\end{array}$ & 0.48 & 0.27 to 0.84 \\
\hline Alcohol consumption (no vs yes) & 0.47 & 0.36 to 0.61 \\
\hline $\begin{array}{l}\text { Visual ability (good/ } \\
\text { impaired)*smoking (never vs yes/had } \\
\text { ever) }\end{array}$ & 0.43 & 0.26 to 0.71 \\
\hline $\begin{array}{l}\text { Visual ability (good/impaired)*taking } \\
\text { a walk ( } \geq 3-4 \text { times/week vs } \leq 1-2 \\
\text { times/week) }\end{array}$ & 0.26 & 0.14 to 0.47 \\
\hline
\end{tabular}

${ }^{a} \mathrm{Age}$ was treated as continuous variable and fixed in the model. $\mathrm{SRH}$, self-rated health. 
Table 5 The multivariate logistic regression analysis of the factors associated with good $\mathrm{SRH}$ among the older men with different visual ability

\begin{tabular}{lll}
\hline & \multicolumn{2}{l}{ OR } \\
\cline { 2 - 3 } Variables & Value & $\mathbf{9 5 \%} \mathbf{C l}$ \\
\hline $\begin{array}{l}\text { Good visual ability ( } \mathrm{n}=1023) \\
\text { Age (years) }\end{array}$ & 1.04 & 1.01 to 1.07 \\
$\begin{array}{l}\text { Chronic disease (not present } \\
\text { vs present) }\end{array}$ & 4.43 & 3.29 to 5.96 \\
$\begin{array}{l}\text { Participating in entertainment } \\
\text { (yes vs no) }\end{array}$ & 1.90 & 1.34 to 2.69 \\
$\begin{array}{l}\text { Taking a walk ( } \geq 3-4 \text { times/ } \\
\text { week vs } \leq 1-2 \text { times/week) }\end{array}$ & 1.79 & 1.32 to 2.44 \\
$\begin{array}{l}\text { Filial piety (good vs poor) } \\
\begin{array}{l}\text { Alcohol consumption (no vs } \\
\text { yes) }\end{array}\end{array}$ & 1.75 & 1.06 to 2.89 \\
\hline
\end{tabular}

Poor visual ability $(\mathrm{n}=684)$

\begin{tabular}{lll}
\hline Age (fixed) $)^{\mathrm{a}}$ & 1.04 & 1.00 to 1.08 \\
\hline $\begin{array}{l}\text { Taking a walk }(\geq 3-4 \text { times/ } \\
\text { week vs } \leq 1-2 \text { times/week) }\end{array}$ & 6.10 & 3.68 to 10.11 \\
$\begin{array}{l}\text { Participating in entertainment } \\
\text { (yes vs no) }\end{array}$ & 3.83 & 2.40 to 6.09 \\
$\begin{array}{l}\text { Hearing ability (good vs } \\
\text { impaired) }\end{array}$ & 2.35 & 1.45 to 3.82 \\
$\begin{array}{l}\text { Smoking (never vs yes/had } \\
\text { ever) }\end{array}$ & 2.34 & 1.47 to 3.73 \\
$\begin{array}{l}\text { Quality of sleep (good vs } \\
\text { impaired) }\end{array}$ & 2.01 & 1.30 to 3.12 \\
$\begin{array}{l}\text { Going out alone to distant } \\
\text { places (can vs cannot) }\end{array}$ & 1.89 & 1.18 to 3.04 \\
\hline $\begin{array}{l}\text { Alcohol consumption (no vs } \\
\text { yes) }\end{array}$ & 0.43 & 0.27 to 0.69 \\
\hline
\end{tabular}

${ }^{\text {aAge }}$ was treated as continuous variable and fixed in the model. $\mathrm{SRH}$, self-rated health.

a walk, not the absence of chronic disease, tended to be crucial in maintaining mobility function. Thus, taking a walk strongly affects the perception of health status among older men with poor visual ability. Because taking a walk is the most feasible physical activity for the older adults, encouraging them to engage in this kind of exercise should be enhanced for all older adults, especially those with poor vision from the standpoint of good SRH.

Social activity was reported to be an important risk factor in relation to SRH. ${ }^{11}$ A previous study ${ }^{33}$ reported that more social network is beneficial to fostering trust and cooperation, which leads to the performance of many social-related behaviours, and thereby contributes to the well-being of participants. ${ }^{9}$ In our study, we also found a significant association between participating in entertainment and $\mathrm{SRH}$, and this association was the second strongest in both groups, even if the involvement of participating in entertainment in the good visual group $(72 \%)$ was nearly $21 \%$ higher than the poor visual group $(51 \%)$. In our previous study conducted among Japanese older adults living alone, ${ }^{11}$ the same conclusion was also drawn. Thus, participating in entertainment could be an important risk factor for $\mathrm{SRH}$ in the older adults regardless of visual ability. How to increase the involvement of participating in entertainment of the older adults, especially the individuals with poor visual ability should be focused by the healthcare system.

Hearing ability is another important sensory ability. Previous studies ${ }^{173435}$ revealed that sensory impairment influences the health status of the older adults. In our study, the effect of impaired hearing ability was also shown to be important for the older adults with poor visual ability; $66.2 \%$ of participants also had hearing problems, which coincided with Chia's findings. ${ }^{34}$ By contrast, less than one-third (29.6\%) of individuals who had good visual ability reported impaired hearing ability. Because dual sensory impairments tended to be more harmful to the quality of life of the older adults than a single sensory impairment, ${ }^{35}$ this might be the reason why the effect of hearing ability was only detected in the group with poor visual ability.

Smoking and alcohol consumption have also been documented to be important risk factors for $\mathrm{SRH}^{36}$ In our study, the effect of smoking and alcohol consumption were shown to be significant, especially for the people with poor vision. Because smoking had been shown to impair visual ability and is related to many diseases, ${ }^{37}$ smoking was expected to accelerate the deterioration of perceived health status among people who already had poor visual ability. Thus, a strong effect on SRH was found. Alcohol consumption was shown to have a positive association with good SRH in both groups. Heavy drinking seems to be impossible for the older adults, whereas, modest drinking contributes to health status, ${ }^{38}$ but we did not measure alcohol consumption in detail. This finding needs to be confirmed in a corollary study.

Filial piety represents the Chinese tradition according to Confucian culture. In China, traditional Confucian teachings have been regarded as the Chinese major spirit for thousands of years. Although the older generation has adapted to lower filial expectation for the younger generation with industrialisation and urbanisation of the societies, filial responsibility in China is still supposed to demonstrate how devoted the children are to the parents, such as showing respect, honouring/promoting the public prestige of the parents, and taking care of the parent whether healthy or sick. ${ }^{39}$ The filial piety duty of children has a considerable effect on the physical and mental health status of the parents. ${ }^{29}$ Our results also revealed a stronger association with good SRH among older men with good visual ability; however, for the older adults with poor visual ability, the effect was not dominant to life style factors, social activity and physical condition on multivariate analysis even though the effect was significant on univariate analysis $(\mathrm{OR}=2.99)$. Given the prominent influence of 
Chinese tradition according to Confucian culture, the filial piety duty of children to their parents should still be enhanced with the purpose of maintaining and improving the perceived health status of the older adults.

In addition, the quality of sleep and going out alone to distant places were shown to be associated with SRH in the poor visual ability group. Poor quality sleep may cause depressed emotions ${ }^{40}$ and worsen an individual's perception of SRH, especially for the people who already have visual problems. With respect to going out alone to distant places, our previous study conducted among the older adults living alone $^{11}$ already showed that this capacity had a crucial effect on SRH because this ability could be the determinant of independent daily life. For community-dwelling older adults with poor visual ability, going out alone to distant places tended to have a similar effect.

Our present study had several limitations. First, the measurements of smoking and alcohol consumption were simplistic and broad, which might weaken the assessment of the effects. Second, this study was limited by the crosssectional design. The causality relationships between associated factors and SRH could not be drawn in the present study. Therefore, further cohort studies should be conducted to achieve this aim.

\section{CONCLUSION}

This is the first population-based study focusing on visualspecific risk factors to SRH among older men without cognitive impairment in urban areas of China. In this study, double-cognitive screens were performed. Our results indicated that the good SRH status, even among the older adults with good visual ability, was at a low level. The risk factors for SRH differed between individuals with good and poor visual ability. Although physical conditions, lifestyle factors, social activity and social psychological factors had considerable associations with SRH of older men, chronic disease had a significant effect on the SRH of older men with good visual ability and taking a walk was prominent for older men with poor visual ability. Our findings suggest that visual-appropriate health education and support should be considered while providing healthcare for the older adults from the viewpoint of SRH.

Contributors Conceptualisation: WS. Data curation: WY and JH. Formal analysis: TZ. Funding acquisition: WS. Investigation: WY and JH. Methodology: BW and WS. Supervision: WS. Writing —original draft preparation: WY. Writing—review and editing: WS. Guarantor: WS.

Funding This research was funded by the National Natural Science Foundation of China [grant number: 81102193$]$.

Disclaimer The funding agencies are not responsible for the opinions presented in the manuscript. The funding bodies had no influence on the conduct of the study or the interpretation of the results.

Competing interests None declared.

Patient consent for publication Not required.

Ethics approval The study protocol and informed consent form received ethics approval from the Committee on Human Experimentation at the China Medical
University. Written informed consent concerning conduct of the survey was obtained from each participant.

Provenance and peer review Not commissioned; externally peer reviewed.

Data sharing statement № additional data sharing available.

Supplemental material This content has been supplied by the author(s). It has not been vetted by BMJ Publishing Group Limited (BMJ) and may not have been peer-reviewed. Any opinions or recommendations discussed are solely those of the author(s) and are not endorsed by BMJ. BMJ disclaims all liability and responsibility arising from any reliance placed on the content. Where the content includes any translated material, BMJ does not warrant the accuracy and reliability of the translations (including but not limited to local regulations, clinical guidelines, terminology, drug names and drug dosages), and is not responsible for any error and/or omissions arising from translation and adaptation or otherwise.

Open access This is an open access article distributed in accordance with the Creative Commons Attribution Non Commercial (CC BY-NC 4.0) license, which permits others to distribute, remix, adapt, build upon this work non-commercially, and license their derivative works on different terms, provided the original work is properly cited, appropriate credit is given, any changes made indicated, and the use is non-commercial. See: http://creativecommons.org/licenses/by-nc/4.0/.

ORCID iD

Wei Sun http://orcid.org/0000-0002-0241-6603

\section{REFERENCES}

1 World Health Organization. Ageing and health, 2021. Available: https://www.who.int/news-room/fact-sheets/detail/ageing-andhealth [Accessed 17 Nov 2021].

2 Jakovljevic MM, Netz Y, Buttigieg SC, et al. Population aging and migration - history and UN forecasts in the EU-28 and its east and south near neighborhood - one century perspective 1950-2050. Global Health 2018;14:30.

3 National Bureau of statistics of China. China statistical yearbook, 2021. Available: http://www.stats.gov.cn/tjsj/ndsj/2021/indexch.htm [Accessed 17 Nov 2021].

4 Falk H, Skoog I, Johansson L, et al. Self-Rated health and its association with mortality in older adults in China, India and Latin America-a 10/66 dementia research Group study. Age Ageing 2017;46:932-9.

5 Campos ACV, Albala C, Lera L, et al. Gender differences in predictors of self-rated health among older adults in Brazil and Chile. BMC Public Health 2015;15:365.

6 DeSalvo KB, Fan VS, McDonell MB, et al. Predicting mortality and healthcare utilization with a single question. Health Serv Res 2005;40:1234-46.

7 DeSalvo KB, Jones TM, Peabody J, et al. Health care expenditure prediction with a single item, self-rated health measure. Med Care 2009;47:440-7.

8 Millán-Calenti JC, Sánchez A, Lorenzo T, et al. Depressive symptoms and other factors associated with poor self-rated health in the elderly: gender differences. Geriatr Gerontol Int 2012;12:198-206.

9 Caetano SC, Silva CMFP, Vettore MV. Gender differences in the association of perceived social support and social network with selfrated health status among older adults: a population-based study in Brazil. BMC Geriatr 2013;13:122.

$10 \mathrm{Hu}$ Y, Gong L, Chen F. Study on influencing factors of the selfrated health in old people in rural areas. Chin $J$ Health Statistics 2013;30:232-4. Article in Chinese.

11 Sun W, Watanabe M, Tanimoto Y, et al. Factors associated with good self-rated health of non-disabled elderly living alone in Japan: a cross-sectional study. BMC Public Health 2007;7:297.

12 Pinillos-Franco S, García-Prieto C. The gender gap in self-rated health and education in Spain. A multilevel analysis. PLoS One 2017;12:e0187823.

13 Wang JJ, Mitchell P, Smith W. Vision and low self-rated health: the blue Mountains eye study. Invest Ophthalmol Vis Sci 2000;41:49-54.

14 Lord SR, Dayhew J. Visual risk factors for falls in older people. J Am Geriatr Soc 2001;49:508-15.

15 Sloan FA, Ostermann J, Brown DS, et al. Effects of changes in self-reported vision on cognitive, affective, and functional status and living arrangements among the elderly. Am J Ophthalmol 2005;140:618.e1-618.e12.

16 Bookwala J, Lawson B. Poor vision, functioning, and depressive symptoms: a test of the activity restriction model. Gerontologist 2011;51:798-808. 
17 Bourque P, Léger C, Pushkar D, et al. Self-Reported sensory impairment and life satisfaction in older French-speaking adults. Can J Nurs Res 2007;39:155171.

18 Steinman BA. Health outcomes associated with self-reported vision impairment in older adults. J Vis Impair Blind 2016;110:385-98.

19 Langelaan M, de Boer MR, van Nispen RMA, et al. Impact of visual impairment on quality of life: a comparison with quality of life in the general population and with other chronic conditions. Ophthalmic Epidemiol 2007;14:119-26.

20 Stevens GA, White RA, Flaxman SR, et al. Global prevalence of vision impairment and blindness: magnitude and temporal trends, 1990-2010. Ophthalmology 2013;120:2377-84.

21 Liu L, Zhang T, Li S, et al. Successful aging among communitydwelling older adults in urban areas of Liaoning Province: the crucial effect of visual ability. Risk Manag Healthc Policy 2021;14:3729-38.

22 Zhang A, Yang D. Investigation of cognitive ability among people in the elderly housing in Chongqing. Chin J Gerontol 2009;29:1943-5. Article in Chinese.

23 Wang Y, Song M, Yu L, et al. Mild cognitive impairment: vascular risk factors in community elderly in four cities of Hebei Province, China. PLoS One 2015;10:e0124566.

24 Mitchell AJ. A meta-analysis of the accuracy of the Mini-Mental state examination in the detection of dementia and mild cognitive impairment. J Psychiatr Res 2009;43:411-31.

$25 \mathrm{Li} \mathrm{H}$, Jia J, Yang Z. Mini-Mental state examination in elderly Chinese: a population-based normative study. J Alzheimers Dis 2016;53:487-96.

26 Horowitz A. The prevalence and consequences of vision impairment in later life. Top Geriatr Rehabil 2004;20:185-95.

27 de Boer MR, Pluijm SMF, Lips P, et al. Different aspects of visual impairment as risk factors for falls and fractures in older men and women. J Bone Miner Res 2004;19:1539-47.

28 Park B, Jun JK, Park J. Cognitive impairment and depression in the early 60S: which is more problematic in terms of instrumental activities of daily living? Geriatr Gerontol Int 2014;14:62-70.

29 Sun W, Aodeng S, Tanimoto Y, et al. Quality of life (QOL) of the community-dwelling elderly and associated factors: a population- based study in urban areas of China. Arch Gerontol Geriatr 2015;60:311-6.

30 Swenor BK, Simonsick EM, Ferrucci L, et al. Visual impairment and incident mobility limitations: the health, aging and body composition study. J Am Geriatr Soc 2015;63:46-54.

31 Turano KA, Broman AT, Bandeen-Roche K, et al. Association of visual field loss and mobility performance in older adults: Salisbury eye evaluation study. Optom Vis Sci 2004;81:298-307.

32 Swenor BK, Muñoz B, West SK. Does visual impairment affect mobility over time? the Salisbury eye evaluation study. Invest Ophthalmol Vis Sci 2013;54:7683-90.

33 Latkin CA, Knowlton AR. Social network assessments and interventions for health behavior change: a critical review. Behav Med 2015;41:90-7.

34 Chia E-M, Mitchell P, Rochtchina E, et al. Association between vision and hearing impairments and their combined effects on quality of life. Arch Ophthalmol 2006;124:1465-70.

35 Kwon H-J, Kim J-S, Kim Y-J, et al. Sensory impairment and healthrelated quality of life. Iran J Public Health 2015;44:772-82.

36 Ishizaki T, Yoshida H, Suzuki T, et al. The association between self-rated health status and increasing age among older Japanese living in a rural community over a 6-year period: a longitudinal data analysis. Gerontology 2009;55:344-52.

37 Zhang X, Kahende J, Fan AZ, et al. Smoking and visual impairment among older adults with age-related eye diseases. Prev Chronic Dis 2011;8:A84.

38 Nakanishi N, Suzuki K, Tatara K. Alcohol consumption and risk for development of impaired fasting glucose or type 2 diabetes in middle-aged Japanese men. Diabetes Care 2003;26:48-54.

39 Cheng S-T, Chan ACM. Filial piety and psychological wellbeing in well older Chinese. J Gerontol B Psychol Sci Soc Sci 2006;61:P262-9.

40 Sun W, Fu J, Chang Y, et al. Epidemiological study on risk factors for anxiety disorder among Chinese doctors. J Occup Health 2012;54:1-8. 